\title{
0 papel da mobilização social na gestão de sistemas de dessalinização no semiárido brasileiro
}

Henrique Pinheiro Veiga ${ }^{1}$

Renato Saraiva Ferreira ${ }^{2}$

Luis Henrique Cunha ${ }^{3}$

\begin{abstract}
RESUMO: A disponibilidade hídrica nas zonas rurais do semiárido brasileiro é fator limitante para garantir condições de sobrevivência e bem-estar das populações. Uma alternativa é a utilização de sistemas de dessalinização para tratar as águas subterrâneas salobras encontradas sob as rochas cristalinas. Historicamente, esses sistemas apresentam problemas quanto sua manutenção e gestão. Para garantir sua eficiência é importante o envolvimento das comunidades. Nesse sentido, o Programa Água Doce visa estabelecer uma política pública de acesso à água, incorporando os cuidados socioambientais na gestão desses sistemas. Sua metodologia desperta a conscientização socioambiental dos atores em um processo de formação de sujeitos ecológicos.
\end{abstract}

Palavras- chave: dessalinização de água; mobilização social; educação ambiental.

\section{INTRODUÇÃO}

O problema da disponibilidade hídrica em regiões semiáridas é fator limitante para a garantia das condições de sobrevivência e bem-estar de suas populações. Historicamente os governos, tanto federal como os estaduais, vêm atuando com o objetivo de implantar infraestruturas capazes de disponibilizar água em quantidade e qualidade suficientes para garantir o abastecimento humano e animal e viabilizar a irrigação. No entanto, esses esforços não têm sido suficiente para resolver o problema da escassez de água, tornando essas áreas vulneráveis à ocorrência de estiagens, especialmente em regiões rurais difusas. Diferentemente do restante do país, o semiárido brasileiro possui quase metade da população vivendo em áreas rurais, muitas delas ainda sofrem com a falta de água para os diversos usos (BRASIL, 2005).

Uma das alternativas para garantir o acesso à água nessas regiões é o aproveitamento de águas subterrâneas. Todavia, no que se refere à disponibilidade de água subterrânea, como o subsolo nordestino é constituído por aproximadamente $80 \%$ de rochas cristalinas, há predominância de poços com baixa vazão (na ordem de $1 \mathrm{~m} 3 / \mathrm{s}$ ), além disso, apresenta águas com teor elevado de sais, tornando-as impróprias para o consumo humano (CIRILO 2008).

A fim de contornar o problema da salinidade das águas subterrâneas os governos federais, estaduais e locais têm utilizado a tecnologia da dessalinização para garantir

1 Analista Ambiental do Departamento de Revitalização de Bacias Hidrográficas na Secretaria de Recursos Hídricos e Ambiente Urbano.

2 Coordenador Nacional do Programa Água Doce e Diretor-Substituto do Departamento de Revitalização de Bacias Hidrográficas na Secretaria de Recursos Hídricos e Ambiente Urbano.

3 Coordenador do componente de mobilização social do Programa Água Doce. Doutor em Desenvolvimento

Sustentável do Trópico Úmido pela Universidade Federal do Pará (UFPA) e professor da Universidade Federal de Campina Grande (UFCG).

Revbea, Rio Grande, 7: 16-20, 2012. 
água potável para o consumo humano em comunidade rurais do semiárido. Desde meados da década de 80 , o poder público vem implantando sistemas de dessalinização nessas comunidades, no entanto, grande parte desses equipamentos apresenta diversos problemas e na sua maioria se encontram parados ou quebrados. O principal motivo do sucateamento e quebra desses equipamentos é a falta de manutenção preventiva e de cuidados na gestão desses sistemas. Para garantir a eficiência em sua gestão se faz importante o envolvimento das comunidades e dos diversos atores sociais. Nesse sentido o Ministério do Meio Ambiente formulou o Programa Água Doce (PAD) que tem por objetivo estabelecer uma política pública permanente de acesso à água por meio do aproveitamento sustentável das águas subterrâneas salinas ou salobras, incorporando os cuidados ambientais e sociais na gestão de sistemas de dessalinização.

O PAD está estruturado em componentes, são eles: gestão, pesquisa, sistemas de dessalinização e sistemas produtivos. O componente de gestão compreende os subcomponentes: formação de recursos humanos, diagnóstico técnico e ambiental, mobilização social, sustentabilidade ambiental, manutenção dos sistemas, entre outros. O subcomponente de mobilização social é coordenado pelo Laboratório de Sociologia Aplicada da Universidade Federal de Campina Grande e executado pela equipe de técnicos capacitados pelo programa. Tem como objetivos: a) contribuir para o estabelecimento de bases sólidas de cooperação e participação social na gestão de sistemas de dessalinização (núcleos locais de gestão); b) colaborar no processo de elaboração e definição de acordos de gestão; c) mediar à interlocução, as negociações e os conflitos de interesses entre os diferentes atores sociais envolvidos na gestão dos sistemas de dessalinização.

O acordo de gestão é um documento elaborado e aprovado pela comunidade que contém as regras que irão orientar os direitos e deveres de todas as pessoas beneficiadas pela água proveniente do dessalinizador. É assinado por todas as famílias que recebem água do sistema e também por representantes das instituições públicas que irão apoiar sua gestão. Além disso, ajuda a resolver os conflitos internos e possibilita que a própria comunidade tome as decisões relacionadas à gestão do sistema de dessalinização. O espaço criado para a elaboração e discussão desse instrumento de gestão estimula a implementação de alternativas de participação, garantindo o acesso à informação e a consolidação de uma participação plural nos aspectos inerentes às relações sociedade-natureza. A educação ambiental enfatiza os processos participativos na promoção de um desenvolvimento sustentável. No artigo "Educação Ambiental, Cidadania e Sustentabilidade" Jacobi (2003) enfatiza a necessidade de estimular uma participação mais ativa da sociedade no debate de seus destinos, como uma forma de estabelecer um conjunto socialmente identificado de problemas, objetivos e soluções.

O presente trabalho traz uma reflexão sobre a importância da mobilização social na gestão de sistemas de dessalinização no semiárido brasileiro relacionando-o com referenciais teóricos de educação ambiental. Entende-se que o processo desencadeado pelas atividades de mobilização social é um passo importante para a construção de uma consciência ambiental e formação de sujeitos ecológicos. Além disso, configura-se como um espaço para o desenvolvimento de uma educação ambiental não formal.

\section{MOBILIZAÇÃO SOCIAL NA GESTÃO DE SISTEMAS DE DESSALINIZAÇÃO E A FORMAÇÃO DE SUJEITOS ECOLÓGICOS}

Um dos maiores desafios do Programa Água Doce é contribuir para a criação de estruturas permanentes de gestão dos sistemas de dessalinização - tanto nos estados quanto nos municípios e nas comunidades. A experiência de programas anteriores mostra que instalar ou recuperar sistemas de dessalinização não é suficiente para garantir a oferta continuada de água de boa qualidade para as famílias do semiárido. É preciso, também, investir na organização de mecanismos de gestão que viabilizem o funcionamento dos sistemas de dessalinização a médio e longo prazo.

Revbea, Rio Grande, 7: 16-20, 2012. 
As ações de mobilização social do PAD visam despertar a conscientização socioambiental, por meio de atividades nas comunidades e escolas e em eventos culturais, artísticos e religiosos. O objetivo é garantir a autonomia da comunidade para que elas assumam efetivamente a gestão dos sistemas de dessalinização e estabelecer um processo participativo junto às comunidades locais, envolvendo diversos setores atuantes como prefeituras, igrejas e movimentos sociais. Suas ações, integradas às atividades dos componentes técnicos e ambiental, focalizam a construção dos mecanismos de gestão que objetivam o estabelecimento de bases sólidas de cooperação e participação social na gestão desses sistemas.

As atividades do programa estão pautadas na ideia de que é mais importante ajudar os atores sociais envolvidos com a gestão dos sistemas de dessalinização a encontrar as soluções para os problemas, do que oferecer modelos prontos para mediação dos conflitos e de impor regras de acesso e uso da água dessalinizada.

Outro aspecto importante é fazer com que as populações beneficiadas possam, a partir do conhecimento de sua realidade, ter uma visão crítica e transformadora do seu ambiente. Ou seja, pretende-se que essas populações se sintam parte do ambiente, que possui características próprias. Dessa forma essas comunidades se tornam capazes de proteger e mudar o seu meio, incorporando técnicas e abordagens que permitam a sua melhoria. Portanto suas ações visam à construção da noção de cidadania pelas populações beneficiadas. Conforme Reigota (2008) esse processo envolve "sentimentos e identidades de pertencimento" que garantem a busca pela autonomia da comunidade. Jacobi relaciona os conceitos de cidadania e educação ambiental afirmando que "cidadania tem a ver com a identidade e o pertencimento a uma coletividade. A educação ambiental, como formação e exercício da cidadania, refere-se a uma nova forma de encarar a relação do homem com a natureza" (JACOBI, 2003).

Reconhecer e respeitar as estruturas de organização social, identificar as lideranças locais e aproveitar o potencial das formas tradicionais de superação dos dilemas sociais são ações imprescindíveis à construção de mecanismos efetivos de gestão dos sistemas de dessalinização e de controle social.

As ações de mobilização social desse programa ocorrem em três momentos principais que, mesmo estando profundamente interligados, apresentam-se aqui como fases separadas:

\section{a) Diagnóstico social}

É a primeira ação desencadeada por esse componente. No diagnóstico não é possível apreender toda a dinâmica de organização da vida comunitária, os conflitos internos e os diferentes grupos de interesse em uma primeira visita. Porém esse passo é importante para levantar informações básicas para a realização das ações previstas por esse componente, tais como:

I) Potenciais beneficiários diretos e indiretos do PAD e os demais atores (do setor público e da sociedade civil) interessados no processo;

II) Conflitos e problemas que levaram à desativação ou ao funcionamento inadequado dos dessalinizadores no passado (na hipótese de existir dessalinizador desativado na comunidade);

III) Formas de organização social e das lideranças locais que possam colaborar no processo de gestão;

IV) Relações entre a comunidade e as esferas políticas, econômicas e culturais do município;

V) Formas de organização produtiva na comunidade e o envolvimento 
em outros projetos ou programas que objetivem o desenvolvimento da comunidade.

Essa fase corrobora a tese de Ruscheinsky (2004), que afirma que para gerar um processo educativo alicerçado em atitudes ecológicas conscientes, o primeiro passo consiste em compreender as razões e os significados atribuídos a atitudes, comportamentos que entendemos ser contrários a uma perspectiva ambiental. No caso dos sistemas de dessalinização esse diagnóstico permite levantar os aspectos relacionados ao uso sustentável de um recurso ambiental escasso na região.

b) Construção dos mecanismos de gestão local dos sistemas de dessalinização

Os sistemas de dessalinização são estruturas coletivas, ou seja, não são passíveis de apropriação privada. E mesmo quando a gestão desses sistemas inclui o poder público, ainda assim permanece o caráter coletivo do acesso e uso dos sistemas e da água de boa qualidade. A ideia é trabalhar com as comunidades para a construção de soluções cooperativas para os problemas de gestão dos sistemas de dessalinização, focalizando os acordos locais que venham a facilitar a ação coletiva.

As regras que regulam os comportamentos de todos os envolvidos são definidas por meio de acordos. Para elaborar esse instrumento de gestão o papel da informação é fundamental. Os técnicos estaduais responsáveis pela mediação na elaboração dos acordos devem fornecer informações, acessíveis a toda comunidade, acerca dos aspectos ambientais e técnicos inerentes aos sistemas. Tal aspecto corrobora com o exposto por Jacobi que cita a necessidade de incrementar os meio de informação e o acesso a eles. Para o autor, trata-se de promover o crescimento da consciência ambiental, expandindo a possibilidade da comunidade participar em um nível mais alto no processo decisório, como forma de fortalecer sua corresponsabilidade na gestão dos sistemas (Jacobi, 2003).

Essas regras, estabelecidas nos acordos de gestão, deverão ser continuamente desenvolvidas e aperfeiçoadas, de modo a atender às oportunidades e limitações que certamente surgirão devido à natureza dinâmica da vida social. Um sistema de gestão comunitária dos dessalinizadores será sempre um trabalho em progresso, que precisa ser permanentemente monitorado e avaliado.

c) Monitoramento da gestão feita pelas comunidades atendidas pelo programa.

Essa etapa é planejada com as comunidades beneficiadas, na ocasião da formulação dos acordos para a gestão dos sistemas de dessalinização. Além de representantes dessas comunidades, os técnicos dos núcleos estaduais também participam dessa etapa do processo.

\section{CONSIDERAÇÕES FINAIS}

Como podemos perceber a proposta de mobilização social do PAD para a gestão sustentável de sistemas de dessalinização busca compreender os espaços sociais constituídos e os conflitos envolvidos no processo, sejam eles relacionados à distribuição e qualidade da água ou à operação e manutenção desses sistemas. Outro aspecto importante é a construção de uma percepção da importância desse recurso ambiental escasso na região. Embutir nos atores envolvidos uma atitude consciente que promova a formação de sujeitos ecológicos. A produção desses conhecimentos e percepções deve contemplar as inter-relações do meio natural com o social, o papel dos diversos atores envolvidos e as formas de organização social, rumo a uma gestão com ênfase na sustentabilidade socioambiental (JACOBI, 2003).

Vale citar o trabalho de Ruscheinsky (2004). No texto o autor considera importante a avaliação das forças sociais presentes no jogo do poder e a contribuição da sociologia nos debates das questões ambientais para a implementação de uma educação ambiental. 
De acordo com o autor existe a expectativa de que sejam constituídas práticas sociais que promovam a emergência de uma consciência ecológica, que produza efeitos a partir de uma mudança cultural. Na metodologia proposta pelo programa, as práticas e relações sociais visam à construção de uma consciência ecológica. Além disso, propõe-se alterar as estruturas de micropoder instituídas na relação das comunidades com o acesso e distribuição da água. Ainda segundo Ruscheinsky "a construção do saber (ambiental) exige um olhar voltado para os atores que constroem e sustentam os conflitos nas relações sociais".

Podemos ainda relacionar as práticas propostas pelas ações de mobilização social do programa com o que foi citado por Jacobi (2003) sobre a importância do protagonismo dos atores sociais frente aos problemas ambientais e a implementação de políticas públicas. Segundo o autor, deve-se "estimular práticas que reforcem a autonomia e a legitimidade de atores sociais que atuam articuladamente numa perspectiva de cooperação". Ainda de acordo com o texto, isto representaria "a possibilidade de mudar as práticas prevalecentes, rompendo com as lógicas da tutela e regulação, definindo novas relações baseadas na negociação, na contratualidade e na gestão conjunta de programas e atividades, o que introduz um novo significado nos processos de formulação e implementação de políticas ambientais".

Esse espaço não formal de educação, trabalhado pelas ações de mobilização social, visa um processo de humanização de seus atores sociais. Como afirma Carvalho (2004), este processo é um dos passos para a construção de uma educação ambiental crítica e transformadora e contribui para a formação de um sujeito humano enquanto ser social e historicamente situado. A autora enfatiza ainda que um projeto educativo crítico "rompe com uma visão de educação determinante da difusão e do repasse de conhecimentos, convocando-a a assumir sua função de prática mediadora na construção social de conhecimentos implicados na vida dos sujeitos [...] a educação como instância formativa de sujeitos sociais emancipados, isto é, atores da própria história".

\section{REFERÊNCIAS}

BRASIL. Ministério da Integração Nacional. Secretaria de Políticas de Desenvolvimento Regional. Nova delimitação do Semiárido Brasileiro. Brasília, 2005. 35 p.

CARVALHO, I. C. M. Educação ambiental: a formação do sujeito ecológico. 4 ed. São Paulo: Cortez Editora, 2008.

CIRILO, J. A. Políticas Públicas de Recursos Hídricos para o Semiárido Brasileiro. Estudos Avançados, São Paulo, v. 63, p. 61-82, 2008.

JACOBI, Pedro Roberto. Educação ambiental, cidadania e sustentabilidade. Cadernos de Pesquisa, São Paulo, v. 118, p. 189-206, mar. 2003.

REIGOTA, M. A. S. Cidadania e educação ambiental. Psicologia e Sociedade, Porto Alegre, v. 20, p. 61-69, 2008.

RUSCHEINSKY, A. Atores Sociais e Meio Ambiente. In: Identidades da Educação Ambiental Brasileira. Brasília: MMA, 2004, p. 51-64. 